\title{
Exploration on the Piano Course Teaching Reform of Preschool Education Major
}

\author{
Yichen Xie \\ (Xijing University) \\ Xijing University, No.1 Xijing Road, Chang'an District, Xi'an City, Shaanxi Province ,China \\ 2349585721@qq.com
}

Keywords: Preschool education major; Piano course; Teaching reform

\begin{abstract}
As the king of Musical Instruments, the piano has always been a hot course in universities. As a science of technical application that artistic and creative comprehensive, it is also a compulsory course for preschool education majors. With the improvement of living standard, the piano holding rate has been greatly improved. The number of students has increased dramatically, but the performance level is still at a relatively low stage. At present, the development of piano education in colleges and universities needs to be effectively improved, and new methods should be developed to integrate students' level. This paper mainly discusses how to reform the teaching of piano education in preschool education major.
\end{abstract}

\section{Introduction}

Piano is a science of technical application that artistic and creative comprehensive. It is a course of "theory + practice" and a compulsory course for vocational skills. Its main purpose is to cultivate students' ability to sing accompaniment for others and to sing while playing. Through the study in the class, students will not only have a solid theoretical foundation of music, but also have the preliminary skills of arranging children's songs to improvise accompaniment. Through learning, students acquire the skills of playing and singing at the same time, so as to adapt to the current kindergarten's requirements on teacher's ability that transforming school knowledge into practical skills through observation and practice. Based on years of teaching experience accumulated in preschool education specialized courses, and combined with the current practical situation, we put forward the idea of constructing the curriculum setting, textbook compilation and teaching system of piano course.

\section{A Brief Analysis of the Current Status of Piano Education}

Collective Teaching Has Its Advantages and Disadvantages. The higher levels pursuit of education has been the consensus of Chinese people. Colleges and universities are constantly expanding their enrollment, which directly leads to the inability of teachers to teach one-to-one. Piano teaching should be in a small class, but the present situation is a large group of students around one teacher, teaching results naturally decline. Teachers can't teach one-to-one, can't pay more attention to an individual, and students' classroom attention drops. In the form of collective teaching, teachers can only pay more attention to the students who have performance level, but they cannot pay too much attention to the emotional mobilization and innovation ability, so that they cannot timely point out the mistakes of some students. Although collective teaching has certain disadvantages, it cannot be denied that in this way of teaching, students can have a certain sense of tension and have more sense of competition. Students can also carry out discussions among themselves, which makes it easier to digest and absorb knowledge.

Another Current Situation is That Piano Teachers Are Inexperienced. Most of the teachers recruited by universities are graduates from normal universities. They may have graduated from prestigious institutions of higher learning, but after all, they have insufficient practical experience and limited teaching experience, so that they cannot guide students in the teaching process better. 
Piano belongs to the practice discipline. Although theory education is important, the most important thing is how skilled in piano, which requires a long time to practice. Besides, piano performance has strong personal characteristics. Different people play the same music with different effects, and the performance effect is different if the player has a different understanding of the music. A deeper understanding of the repertoire requires not only superb playing skills but also rich life experience and experience for players, which is often lacking for young educators. Therefore, teachers with excellent performance skills, rich emotional experience and certain teaching experience are in short supply, which is also one of the biggest problems of Chinese piano education at present.

There Is Also a Problem on the Piano Education That We Pay More Attention on the Theory Teaching Than the Practice Teaching. This situation is caused by the lack of school equipment and the deviation of teachers' teaching focus. Firstly, the shortage of piano equipment in universities cannot provide sufficient opportunities for students to play. Although the use rate of the piano is high, it is in the position of an accompaniment in most cases, and there are few solo piano pieces. Therefore, the students lack experience of live performance. Secondly, teachers' teaching focuses on theory education, which is also related to the strong academic atmosphere in universities. In such a climate, students' focus is naturally shifted. In order to change such a culture, the university should pay enough attention and support.

Most students in preschool education majors have no access to the piano when they enter the school. From the perspective of enrollment source, music accomplishment of preschool education majors in higher vocational colleges is not optimistic. First of all, the students come from different backgrounds, most of them do not have learning basis. Some students do not have any foundation. Some students have some music foundation, but it's very weak because the heavy study duty in the middle school. After entering the school, such students need a period of piano basic training to enter the teaching stage of improvising. The time is short and the task is heavy.

\section{Why Should Preschool Education Major Learn the Piano Well}

Piano Accompaniment Is a Necessary Teaching Method in Music Course Teaching in Primary Schools and Kindergartens. Piano is a compulsory course for preschool education majors and an indispensable skill course for cultivating qualified kindergarten teachers. In kindergarten music teaching work, piano accompaniment can play a good role in art guidance for children. In the music class in kindergarten, the piano plays a leading role in body rhythm and song and dance drama performance. Teachers often use the piano accompaniment to replace teachers' language guidance, so as to inspire children's understanding and performance of music. Through the rendering of the piano sound, the whole teaching is filled with the atmosphere of music.

The Study of Piano Accompaniment Is Also a Kind of Music Cultivation Training. It can expand learners' artistic vision and improve their piano performance level, and it is conducive to improving the piano performance's singing sense, rhythm sense and visual playing ability, as well as more opportunities for stage practice.

Under the concept of quality education, the cultivation of children's music accomplishment is an indispensable part of kindergarten education. The degree of love and mastery of piano accompaniment learners is not only directly related to the overall quality of children music education teachers, but also has a significant impact on children music education and even the quality of education. In view of this, it is vital importance to develop children teachers' music literacy and working ability. The ability to piano accompaniment is an important part of this important content.

\section{The Idea of Piano Accompaniment Teaching Reform}

Highlight the preschool education professional features and consider piano course integration. In the past, the traditional curriculum was divided into "piano" and "impromptu accompaniment". This traditional course division method is not only diverges the line with the training goal of preschool education major, but also takes a large number of hours. So it is difficult to complete the 
teaching goal, and It is difficult for students to complete the task of improvising after entering the kindergarten. In addition, students have many courses to learn, and there is no need to complete the teaching content like music. Furthermore, the preschool education piano course only lays the foundation for music knowledge and skills needed by children education workers in music activities in kindergarten. Therefore, the piano course setting of preschool education major is integrated according to practical needs and actual conditions such as less class hours, more students and weak foundation of students.

Adopt the Teaching Mode of "Group Class, Group Guidance and Individual Guidance". For a long time, the preschool education students' piano accompaniment class has been taught in the same way as music schools' scheduling and teaching mode, which is usually two periods per week for one academic year. In this way, even little students in music schools can master the skill of improvising accompaniment, not to mention preschool education majors whose teaching foundation is very weak. Therefore, we should adopt a more flexible way of arranging classes and teaching for students' own situation. Through the summary of the teaching practice in these years, we think that the teaching mode can be combined with "group class, group guidance and individual guidance". In the "collective class", teachers mainly teach the theoretical knowledge of impromptu accompaniment, assign homework, select some students' homework and summarize. "Group lessons" by the piano teacher is mainly responsible for checking and correcting the problems of the students' piano performance when playing the accompaniment. For those students with higher piano level and practical level, individual tutoring is carried out to lay a good foundation for their future study. The combination of the piano accompaniment course and the piano basic course teaching through such a teaching method makes the piano accompaniment course work in a two-pronged, comprehensive attack and each breakdown, which not only improves the students' piano playing skills, but also promotes the improvement of the teaching level of accompaniment. We think that it is very useful to construct a new teaching model of "group class, group guidance and individual guidance" from the actual situation.

Give Play to the Teaching Advantages of Digital Piano Classroom. At present, many schools use electric piano classrooms to teach piano accompaniment lessons. Electric piano classroom as a high-tech product includes several or dozens digital pianos that connected through the network. It can make teaching and practice in a complete system that have the breakthrough in traditional music teaching "bottleneck". The classroom can undertake a one-to-many teaching, generally teachers and students can get a piano everyone, teachers can use multimedia in collective teaching and personal guidance. This teaching mode solves the problems that cannot be effectively balanced such as explanation and practice of piano accompaniment teaching, thus improving the quality of on-site teaching, saving teaching time, bringing new vitality to teachers' teaching and making teachers' teaching methods more flexible.

Education Expansion from Students. Education expansion is mainly targeted at students' music accomplishment, which should cultivate students' aesthetic ability, such as the ability to distinguish the superior and inferior cultures, and the ability to create original music and restore. And these raise compared with the theory teaching is very difficult, but it is very necessary. This requires the teacher himself to have a very high performance ability and skill. Teachers should not only teach students the skills of playing, but also guide students to have emotional communication. In the process of playing, students can better mobilize their emotions and enrich the emotion of the music.

In the Teaching Process, Teachers Should Pay More Attention to Cultivating Students' Aesthetic Ability and Improving Their Ability to Appreciate Art. The cultivation of this ability is limited in the classroom. The most important thing is that students deliberately cultivate themselves in daily life. 


\section{Summary}

The positive factors is the gradual enhancement of education in colleges and universities. There are many problems in the current piano education, the level of teachers is different, the students' basic level and talent are also deffrent, the teaching method is urgently needed to reform, and in the current situation, how to develop the piano education cause will be a problem that education workers should discuss carefully. In order to fundamentally change the dilemma of piano accompaniment teaching, it is necessary to conduct research from the aspects of teaching management, curriculum setting, textbook compilation and teaching system, and finally make the preschool education professional piano accompaniment teaching develop and improve continuously.

\section{References}

[1] Qian Yang. Teachers and children piano teaching arrangement of docking teaching [J/OL]. Yellow River, 2018 (11) : 99 [2018-08-13]. https://doi.org/10.19340/j.cnki.hhzs.2018.11.071. (In Chinese)

[2] Yi Li. Analysis of the importance of demonstration performance in piano teaching [J]. Creation of music,2018(08):168-169. (In Chinese)

[3] Xiaoyu Wu. Exploration and research of piano basic course teaching reform for musicology major in universities [J]. Music creation,2018(08):186-187. (In Chinese)

[4] Yuanyi Sun. Study on the status quo and countermeasures of piano teaching in Chinese universities [J]. Voice of the Yellow River,2018(10):64-65. (In Chinese)

[5] Shaonan Han. Reflections on the practice of piano teaching in normal universities [J]. Voice of the Yellow River,2018(10):101. (In Chinese)

[6] Ting Zheng. Pre-school education professional piano classroom exploration [J]. Voice of the Yellow River,2018(09):67-68. (In Chinese)

[7] Yayun Huang. Practical exploration of pre-school education professional piano improvisation teaching [J]. Journal of ningbo education college, 2008,20(03):27-30. (In Chinese)

[8] Mingjing Zhang. Research on reform of piano course teaching in pre-school education specialty [J]. Art education,2018(11):73-74. (In Chinese)

[9] Jing Zhao. Misunderstandings and countermeasures in the professional piano teaching of education in preschool of normal university [J]. Art evaluation,2018(09):104-105. (In Chinese)

[10] Letian Lu . Status quo and countermeasures of preschool education piano lessons [J]. Popular literature and art,2018(08):191. (In Chinese) 